\title{
Multiple plastic biliary stent placement in the management of large and multiple choledochal stones: single center experience and review of the literature
}

\author{
Hasan Bektaş ${ }^{1}$, Bünyamin Gürbulak ${ }^{1}$, Zeynep Deniz Şahin ${ }^{1}$, Yiğit Düzköylü², Şükrü Çolak ${ }^{1}$, Esin Kabul Gürbulak ${ }^{3}$, \\ Mehmet Emin Güneş", Ekrem Çakar ${ }^{1}$ \\ ${ }^{1}$ Department of General Surgery, Istanbul Training and Research Hospital, Istanbul, Turkey \\ 2Department of Gastroenterological Surgery, Turkiye Yuksek Ihtisas Training and Research Hospital, Ankara, Turkey \\ ${ }^{3}$ Department of General Surgery, Şişli Hamidiye Etfal Training and Research Hospital, Istanbul, Turkey \\ ${ }^{4}$ Department of General Surgery, Istanbul Esenyurt University, Istanbul, Turkey
}

Videosurgery Miniinv 2017; 12 (3): 231-237

DOI: https://doi.org/10.5114/wiitm.2017.69107

\begin{abstract}
Introduction: Endoscopic retrograde cholangiopancreatography $(E R C P)$ with sphincterotomy is the first step treatment modality of choledocholithiasis. In spite of an extended sphincterotomy, 10-15\% of complex choledochal stones (larger than $15 \mathrm{~mm}$ and/or more than 3 stones) cannot be removed and recurrent ERCP procedures may be needed. Aim: To evaluate the role and efficiency of multiple biliary stent application in the treatment of large and multiple choledochal stones.

Material and methods: Patients with complex choledochal stones and patients with inadequate choledochal clearance during ERCP were included in the study. The study group was divided into 2 groups as the placement of single $(n=27$ patients) or multiple stents ( $n=58$ patients). After a mean time interval of 21 days (10-28), the ERCP procedure was tried for the second time and a stent was placed in case of recurrence.

Results: Successful biliary drainage was provided in both groups. The decrease in the longitudinal or transverse size of the stones after stent placement was found to be statistically significant in both groups $(p=0.001)$. Cholestatic enzymes (alkaline phosphatase (ALP), $\gamma$-glutamyltransferase (GGT)) and bilirubin levels decreased significantly in both groups following stenting $(p=0.001)$. Additionally, multiple stents functioned as a bridge starting from the first ERCP to full clearance in patients with large and multiple stones which could not be removed at once and saved them from the possible morbidities of an invasive operation.

Conclusions: Endoscopic multiple biliary stent placement should be preferred in the treatment of patients with complex choledochal stones and high rates of co-morbidity, as a safe alternative to surgery.
\end{abstract}

Key words: endoscopic retrograde cholangiopancreatography (ERCP), choledocholithiasis, multiple plastic biliary stents.

\section{Introduction}

Endoscopic retrograde cholangiopancreatography (ERCP) with sphincterotomy is the first step treatment modality of choledocholithiasis. In spite of an extended sphincterotomy, $10-15 \%$ of complex choledochal stones (larger than $15 \mathrm{~mm}$ and/or more than 3 stones) cannot be removed and recurrent ERCP procedures may be needed [1, 2]. Especially in

\section{Address for correspondence}

Bünyamin Gürbulak MD, Department of General Surgery, Istanbul Training and Research Hospital, 34098 Istanbul, Turkey,

phone: +90 5554883025, fax: +90 2124366258, e-mail: bgurbulak@gmail.com 
elderly patients, the percentage of full clearance is reported to be low [3-6]. Complex stones, periampullary diverticula, biliary anatomy with anomalies (duct tortuosity or strictures), and history of gastric, duodenum or pancreatic surgery are among the reasons for failure in extraction of stones with ERCP [7]. Extracorporeal shock wave lithotripsy (ESWL), electrohydraulic or laser lithotripsy or chemical melting can be used alone or in combination with ERCP in the treatment of complex stones. Although these are effective methods, they are harder to find in every center and the procedures take a longer time [8]. Unfortunately, elderly patients with various co-morbidities cannot tolerate prolonged procedures.

Temporary plastic biliary stent placement is a safe and alternative procedure that can provide biliary drainage and function as a bridge until later procedures for stone removal in high-risk patients with various comorbidities in whom the initial ERCP has failed [9-12]. Short-term biliary stent placement can lead to a decrease in the size or degradation of the stones and improve the success of upcoming removal procedures [13]. Although the efficacy of ERCP and biliary stenting is known in elderly patients, published literature about the effects of multiple biliary stenting in treatment is still limited.

\section{Aim}

In our study, we evaluated high-risk patients with large and multiple choledochal stones which would be hard to extract despite extended sphincterotomy in the recent 2 years at our clinic. We did not perform a sphincterotomy initially in all the patients, or after performing one, we placed 1 or 2 stents and increased the number of stents until providing complete clearance of stones without the need for surgery. All patients' records were obtained from institutional based computer software and later we evaluated the demographics of patients and results retrospectively to analyze the safety and efficacy of multiple biliary stenting.

\section{Material and methods}

Following the approval of the ethics committee and obtaining informed consent, patients with highrisk comorbidities and complex choledochal stones in whom we had performed therapeutic ERCP between January 2014 and June 2016 were included in the study. They were divided into 2 groups as the first group (group 1) with a single stent and the second group (group 2) with multiple stents.

In both groups, patients were over 65 years old, with complex stones that had been defined before, and all were high-risk patients with chronic and systemic diseases that had rendered them unable to tolerate a prolonged procedure (cerebrovascular accident, chronic artery disease, chronic obstructive pulmonary disease, etc.), with an ASA scores of 3 or more. Additionally, patients who had not accepted conventional open surgery or patients with juxta-ampullary or interpapillary diverticulum, biliary strictures or bile duct anomalies which could prevent sphincterotomy were included. Patients with a diagnosis of suppurative cholangitis, pancreatic head malignancy, cholangiocellular cancer, hydatid cyst that had opened into the biliary tract, sclerosing cholangitis, or biliary fistula were excluded.

All of the ERCP procedures were performed by the same endoscopist, whose mean number of ERCP per year was over 600. In patients with multiple stones, the number and size were determined with ultrasound, computed tomography or magnetic resonance cholangiopancreatography (MRCP) and the size of the largest stone (longitudinal and/ or transverse) was set as the criterion. In secondary and multiple procedures, the decrease in the size or number of stones was determined compared with the first procedure.

All of the procedures were performed under sedation anesthesia (midazolam $0.05 \mathrm{mg} / \mathrm{kg}+$ pethidine $0.5 \mathrm{mg} / \mathrm{kg}$ ) in a prone or semi-lateral position with a standard side-viewing Pentax duodenoscope. Prophylactic antibiotics and analgesics were administered. Following the cannulation with the ERCP catheter and cholangiography, in case of a subtotal clearance of stones, a plastic stent of $8.5 \mathrm{Fr}$ or $10 \mathrm{Fr}$ (Boston Scientific) size was placed over the guidewire (with/without sphincterotomy) with its distal end in the duodenum. A second stent was placed depending on the symptoms of the patient or size of the stone and the patient was called for 3 weeks later. Chemical melting of stones was not performed in any of the patients. In later ERCP sessions, if there was a decrease in the size of the stone, following the removal of stents with polypectomy snare or rattooth foreign body snare, stones were cleared with standard ERCP processes (balloon sphincterotomy, basket extraction, mechanic lithotripsy, etc.). 

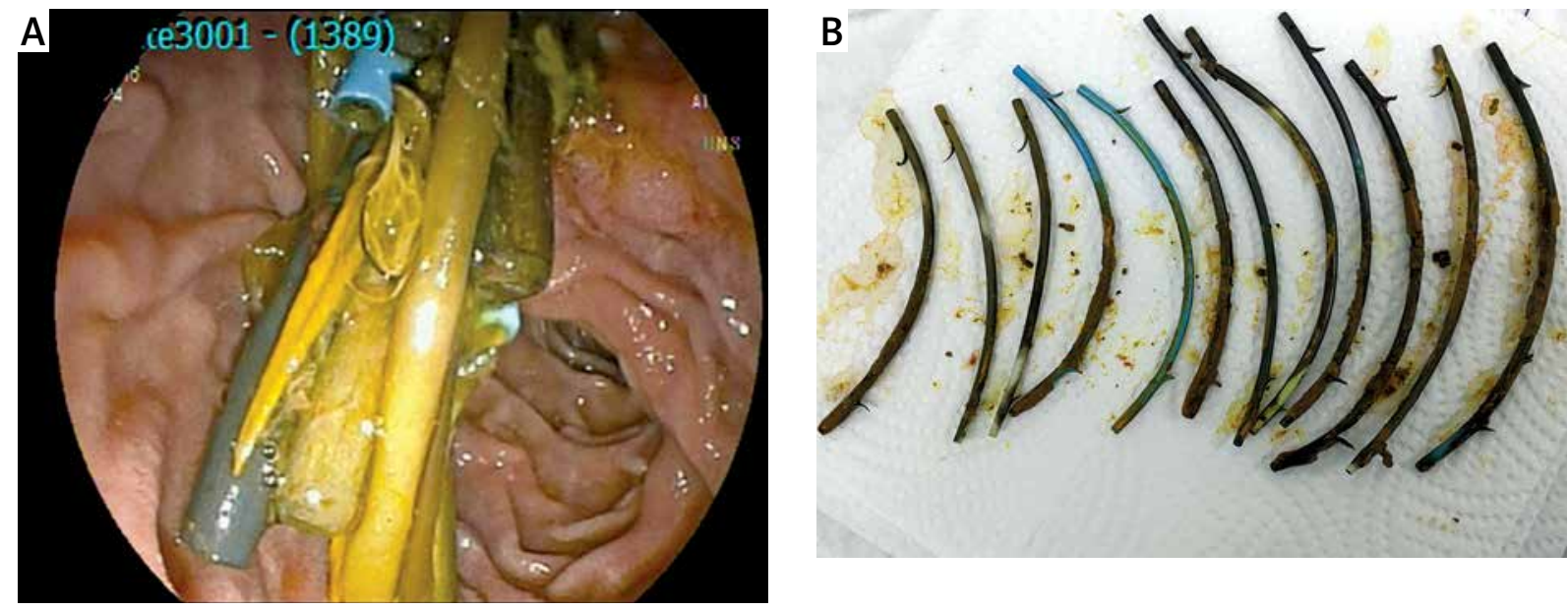

Photo 1. A - ERCP image of multiple plastic biliary stents. B - Removed multiple biliary stents of same patient

Demographics of patients (age, gender), comorbid diseases, clinical features, complications of ERCP and stenting, successful or failed stone removals were registered.

\section{Statistical analysis}

The SPSS program was used for the evaluation of registered data. Mean test and standard deviation was performed for continuous and categorical variables. Student's $t$ test or Wilcoxon rank sum test was used for continuous variables and Fisher's exact test or $\chi^{2}$ for categorical data. Kaplan-Meier analysis was performed for the time interval of stent patency. A $p$-value under 0.05 was accepted to be statistically significant.

\section{Results}

A total of 85 patients (group 1: 27, group 2: 58) were included in the study. Forty-two of the patients were male and 43 were female, with the mean age of 66.9 (28-92). A single plastic stent was placed in the first group (31.7\%) and multiple plastic stents (minimum 2) were placed in the patients of group 2 (68.2\%). In group 2, the average number of applied stents was 4.08 (2-12) (Photos $1 \mathrm{~A}, \mathrm{~B})$.

The mean numbers of ERCP sessions in groups 1 and 2 were $2.74(2-5)$ and $5.18(2-19)$, respectively $(p=0.02)$. Mean duration of the overall endoscopic therapy was 76.51 (21-161) days in group 1 and 277.5 (18-2326) in group 2.

Clinical features of the patients at the time of hospital admission are shown in Table I. In group 1, cholangitis was present in 5 patients, jaundice in 14 patients, abdominal pain in 14 patients, and pancreatitis in 9 patients. Those clinical findings were 6 , 42,12 and 15 respectively in the second group. Cholangitis and jaundice were statistically more common in group $1(p=0.046$ and $p=0.035)$, while there were no statistically significant differences in means of clinical findings between the two groups. There were no significant differences in demographics or comorbidity rates, either.

The mean size of the choledochus in group 1 was found to be $15.7 \pm 4.6(8-27) \mathrm{mm}$ and $17.2 \pm 5.2$ $(7-40) \mathrm{mm}$ in group $2(p=0.79)$.

The average stent staying time in the choledochus was $76.5 \pm 45.3$ (21-161) days in group 1 and $277.5 \pm 388.3$ (18-2326) days in group 2 , which was significantly longer than group $1(p=0.004)$.

The mean size of choledochal stones (mean \pm SD) was $8.55 \pm 5.71 \mathrm{~mm}$ in group 1 and $16.35 \pm 8.45 \mathrm{~mm}$ in group 2 before stenting. The mean size in group 2 was significantly larger than that in group 2 $(p=0.003)$.

Table I. Clinical features of the patients at the time of hospital admission

\begin{tabular}{|lccc|}
\hline Clinical features & Group 1 $(n)$ & Group 2 $(n)$ & $P$-value \\
\hline Cholangitis & 5 & 6 & 0.046 \\
\hline Jaundice & 14 & 42 & 0.035 \\
\hline Pancreatitis & 9 & 15 & 0.12 \\
\hline Abdominal pain & 14 & 12 & 0.89 \\
\hline
\end{tabular}




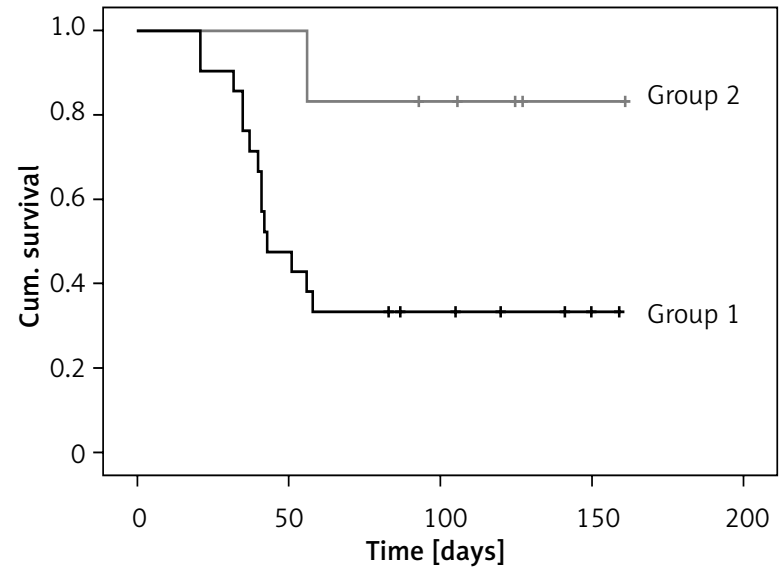

Figure 1. Three-month stent patency rates of group 1 and 2 - Kaplan-Meier analysis

The mean follow-up of patients in groups 1 and 2 were $226.5 \pm 383.7(21-1267)$ and $308.3 \pm 407.8$ (182326) days, respectively $(p=0.034)$.

Following stenting, the mean size of choledochal stones was found to be $7.27 \pm 7.22 \mathrm{~mm}$ in group 1 and $12.23 \pm 6.1 \mathrm{~mm}$ in group 2 . The decrease in the size of choledochal stones was statistically significant when compared to the state before stenting $(p=0.001)$.

Cholestatic enzymes - alkaline phosphatase (ALP), $\gamma$-glutamyltransferase (GGT) - and bilirubin levels decreased significantly in both groups following stenting $(p=0.001)$.

Sphincterotomy during ERCP could not be performed in 3 patients in group 1 and 8 patients in group 2 , because of papilla placement inside of a duodenal diverticulum. Mechanical lithotripsy was performed in 17 and 33 patients in each group, respectively.

When the size of the stone remained the same after the first ERCP session, additional stents were placed in 13 patients in group 1 (48.1\%) and 21 patients in group 2 (36.2\%). Initially those 13 patients in group 1 were transferred to group 2. Finally, in 31 of 34 patients in whom two stents were placed in group 2 complete stone clearance was achieved (91.1\%).

The mean ratio of stent patency was $44.4 \%$ in group 1 and 77\% in group 2, which was significantly higher than the first group, with the Kaplan-Meier method $(p=0.03)$ (Figure 1).

ERCP findings of the patients are shown in Table II.

Hemorrhage due to sphincterotomy was not encountered in any of the patients. In group 1, 11 of the patients had history of cholecystectomy; 3 patients were operated on. In the same group, juxta-diverticular papilla was observed in 2 patients. In 1 of those patients, duodenal perforation occurred during the cannulation of the papilla. In emergency surgery, cholecystectomy, choledochal exploration and T-tube drainage were performed. In the multiple-stent group, juxta-diverticular papilla was observed in 2 and intra-diverticular papilla was observed in other 2 patients.

There were no complications due to biliary stenting. Cholangitis was not encountered in the early term in any of the patients. In one patient in group 1 , acute cholangitis developed on the fifth day, despite successful stenting and drainage. The patient did not

Table II. Characteristics of the patients according to ERCP findings

\begin{tabular}{|c|c|c|c|}
\hline ERCP findings & Group 1 & Group 2 & $P$-value \\
\hline Size of choledochus (mean) $[\mathrm{mm}]$ & 15.7 & 17.2 & 0.79 \\
\hline Stent staying time (mean) [day] & 76.5 & 277.5 & 0.004 \\
\hline Size of choledochal stones at admission (mean) [mm] & 8.5 & 16.5 & 0.003 \\
\hline Size of choledochal stones after stenting (mean) [mm] & 7.2 & 12.2 & 0.001 \\
\hline Follow-up duration (mean) [day] & 226.5 & 308.3 & 0.034 \\
\hline Number of ERCP sessions (mean) & 2.7 & 5.1 & 0.02 \\
\hline Number of sphincterotomies (mean) & 24 & 50 & 0.91 \\
\hline Number of mechanical lithotripsy (mean) & 17 & 33 & 0.77 \\
\hline Number of applied stents (mean) & 1 & 4.08 & - \\
\hline Ratio of stent patency (\%) & 44.4 & 77 & 0.03 \\
\hline
\end{tabular}


accept another ERCP procedure, underwent emergency surgery, and cholecystectomy, choledochal exploration and T-tube drainage were performed. He died at the intensive care unit on postoperative day 5 .

In the multiple stent group, 17 of the patients had a history of cholecystectomy, and 6 patients were operated on. Four of those 6 patients were operated on because they did not want to continue stenting sessions. One patient was operated on because of a cholecystogastric fistula that had developed 30 days after the first ERCP (cholecystectomy, choledochal exploration and primary repair). The last patient was operated on urgently because of acute cholecystitis on the $204^{\text {th }}$ day following multiple stenting. In the same group, another patient died because of his comorbid disorders on the $31^{\text {st }}$ day at the intensive care unit after a successful second ERCP session.

The difference in the rate of stent migration was not statistically significant between the groups (2 patients in group 1 (7.4\%) and 8 patients in group 2 $(13.7 \%))(p=0.655)$. Wirsung duct cannulation and pancreatic stent placement were performed in 2 patients in the first group and in 1 patient in the second group, without any complications such as pancreatitis. Wirsung cannulation was not statistically significant between groups ( $p=0.157)$. The other complications did not show any statistically significant difference between groups (Table III).

\section{Discussion}

Conventional ERCP techniques (such as sphincterotomy, stone extraction with balloon and basket catheterization) can fail in $5-10 \%$ of patients with large and multiple choledochal stones $[7,8]$. The rate of successful extraction decreases with the increasing size of the stone [14]. Patients with older age ( $>65$ ) and concomitant diseases such as cerebrovascular accident, cardiopulmonary disorders or chronic obstructive pulmonary disease are more susceptible to possible complications and are also high-risk patients for surgical interventions. Temporary biliary stenting is a safe alternative by preventing stone impaction and cholangitis until definitive treatment in this patient group $[10,15,16]$

In this study, we aimed to report our cases in which we have performed successful biliary clearance, claiming that multiple biliary stenting provides a reduction in stone size and a better 3-month patency, with a review of up-to-date literature.
Endoscopic biliary stenting was first introduced in the early 1980s [17] and self-expanding metallic stents (SEMS) were shown to be more effective than plastic stents in the late 1980s [18]. The size of biliary plastic stents varies between $5 \mathrm{Fr}$ and $12 \mathrm{Fr}$, their lengths between 1 and $18 \mathrm{~cm}$ [19].

In the literature, $2^{\text {nd }}$ ERCP sessions with stenting have been reported to be successful, with a $70 \%$ rate in removing biliary tract stones $[11,20]$. Additionally, multiple stent placement has been shown to be effective in the long-term treatment of biliary strictures following liver transplantation, with low rates of recurrence and stricture resolution rates up to $70-100 \%$ [21].

Short-term results (3 months) are also consistent with a decrease both in size and number of the stones [13, 15, 22]. In our study, mean size of the stones (mean \pm SD) decreased significantly in both groups $1(7.27 \pm 7.22 \mathrm{~mm})$ and $2(12.23 \pm 6.1 \mathrm{~mm})$ following stent placement $(p=0.001)$.

The mechanism underlying the decrease in size and number of the stones is not clear yet. Respiratory and intestinal movements are thought to have a role with the friction effect. Stenting provides the continuity of biliary drainage by preventing stone impaction in the ampulla. Multiple stent placement can provide more effective biliary drainage, and reduce the amount of duodenogastric reflux and the rate of stent obstruction by tapering the accumulation of calcium bilirubinate. The results of single and multiple stent placements have been compared in patients with biliary strictures following pancreatitis and liver function tests have been shown to come down to normal levels in all of the patients in the second group [23].

Table III. Comparison of complications between groups

\begin{tabular}{|lccc|}
\hline Complications & Group 1 (n) & Group 2 (n) & $P$-value \\
\hline Technical failure & 2 & 2 & 0.67 \\
\hline $\begin{array}{l}\text { Duodenal } \\
\text { perforation }\end{array}$ & 1 & 0 & 0.27 \\
\hline Acute cholangitis & 1 & 0 & 0.27 \\
\hline $\begin{array}{l}\text { Cholecystogastric } \\
\text { fistula }\end{array}$ & 0 & 1 & 0.15 \\
\hline Stent migration & 2 & 8 & 0.655 \\
\hline $\begin{array}{l}\text { Wirsung duct } \\
\text { cannulation }\end{array}$ & 2 & 1 & 0.157 \\
\hline
\end{tabular}


Multiple stenting also rounds the faceted stones by the friction effect and enables the spontaneous passage of stones [14].

Stent obstruction is a complication that may be encountered in the short term, requiring re-stenting $[22,24]$. Although the underlying mechanism is not clear yet, calcium bilirubinate precipitation following bilirubin deconjugation resulting from bacterial colonization on the stent is thought to be responsible [25]. Stents of size $10 \mathrm{Fr}$ have been shown to have a better patency, because larger stents do not provide any advantage when compared to $10 \mathrm{Fr}$ stents [26].

In our study, 3-month patency of multiple stents was found to be better when compared to group 1 $(p=0.03)$, which may be an indicator showing their advantage in biliary drainage.

We observed an increase in the rate of complete stone removal with multiple-stent application. In 12 (92.3\%) of 13 patients and in 19 of 21 patients in group 2 in whom a reduction in the size of stones had not been achieved after the $1^{\text {st }}$ ERCP, multiple stent placement was successful. Additional benefits of multiple stents are their increasing effect on biliary drainage with the 'wicking' phenomenon [8] and papillary dilatation, which is especially useful in patients with juxtadiverticular or paradiverticular localizations without the need for a sphincterotomy.

Expandable biliary stent lithotripsy with covered SEMS is another alternative method that has been defined in the literature in the treatment of choledocholithiasis. This technique has been applied especially in patients with anastomotic biliary strictures and a decrease in the number of ERCP sessions but with recurrence rates of strictures up to $9-47 \%$ [27-29]. Similar to this procedure, we preferred using multiple plastic stents in cases with complex stones without sphincterotomy when the papillae are in risky localizations and provided successful extraction. So we were also aware of the possible complications of endoscopic biliary sphincterotomy such as hemorrhage or perforation, which may be encountered with rates up to $13 \%$ and $11 \%$, respectively [30]. We did not cause any complications due to sphincterotomy in our series.

In our study, we used biliary stenting for choledochal stones which were hard, dangerous or impossible to extract with conventional ERCP, thus shortening the length of the procedural time and avoiding complications due to extra cannulation such as
post-ERCP pancreatitis, cholangitis, hemorrhage or perforation. Post-ERCP cholangitis is reported to have a mortality rate up to $8-20 \%$ [31], but fortunately we did not encounter any. We also did not observe post-ERCP pancreatitis, which is reported to have an incidence of $5 \%$, in any of our cases [13].

Stent migration occurs in a dilated duct, when the stone pushes the stent towards the duodenum or proximal bile ducts [14]. The migration rate is reported to be $5 \%$ for plastic stents [31]. In our series, migration rates were $7.4 \%$ (2 patients) in group 1 and $13.7 \%$ (8 patients) in group 2; the difference was not statistically significant $(p=0.655)$.

The advantage of our study was the fact that all of the ERCP procedures were performed by a single endoscopist. Additionally, the patient and type of procedure selection criteria were defined at the first ERCP procedure, so we did not have bias in our results. A disadvantage of the study is the limited number of cases, which also limits the significance of the statistics. Another limitation was the additional ERCP sessions performed for multiple stents.

\section{Conclusions}

In this study, complete stone extraction was performed successfully in high-risk patients whom conventional ERCP techniques were insufficient, which we believe may contribute to the literature in the light of up-to-date studies as a new method. Although there are increasing data suggesting the advantage of multiple stenting, previous studies usually defined the procedure with 3 or 4 stents, but in our study the mean number of stents was 4.08 [2-12]. We believe that this technique may be a safe and effective alternative for conventional ERCP or surgery in high-risk patients and cases with abnormal papilla localization without the need for sphincterotomy, but multicenter studies with more extended study groups are needed for more certain results.

\section{Conflict of interest}

The authors declare no conflict of interest.

\section{References}

1. Weinberg BM, Shindy W, Lo S. Endoscopic balloon sphincter dilation (sphincteroplasty) versus sphincterotomy for common bile duct stones. Cochrane Database Syst Rev 2006; 4: CD004890. 
2. Freeman ML, Nelson DB, Sherman S, et al. Complications of endoscopic biliary sphincterotomy. N Engl J Med 1996; 335: 909-18.

3. Lauri A, Horton RC, Davidson BR, et al. Endoscopic extraction of bile duct stones: management related to stone size. Gut 1993; 34: 1718-21.

4. Binmoeller KF, Bruckner M, Thonke F, Soehendra N. Treatment of difficult bile duct stones using mechanical, electrohydraulic and extracorporeal shock wave lithotripsy. Endoscopy 1993; 25: 201-6.

5. Sugiyama M, Atomi Y. Endoscopic sphincterotomy for bile duct stones in patients 90 years of age and older. Gastrointest Endosc 2000; 52: 187-91.

6. Binmoeller KF, Schafer TW. Endoscopic management of bile duct stones. J Clin Gastroenterol 2001; 32: 106-18.

7. Tyagi P, Sharma P, Sharma BC, Puri AS. Periampullary diverticula and technical success of endoscopic retrograde cholangiopancreatography. Surg Endosc 2009; 23: 1342-5.

8. Lee TH, Han JH, Kim HJ, et al. Is the addition of choleretic agents in multiple double-pigtail biliary stents effective for difficult common bile duct stones in elderly patients? A prospective, multicenter study. Gastrointest Endosc 2011; 74: 96-102.

9. Ang TL, Fock KM, Teo EK, et al. An audit of the outcome of longterm biliary stenting in the treatment of common bile duct stones in a general hospital. J Gastroenterol 2006; 41: 765-71.

10. Pisello F, Geraci G, LiVolsi F, et al. Permanent stenting in "unextractable" common bile duct stones in high risk patients. A prospective randomized study comparing two different stents. Langenbecks Arch Surg 2008; 393: 857-63.

11. Maxton DG, Tweedle DE, Martin DF. Retained common bile duct stones after endoscopic sphincterotomy: temporary and long term treatment with biliary stenting. Gut 1995; 36: 446-9.

12. Hui CK, Lai KC, Ng M, et al. Retained common bile duct stones: a comparison between biliary stenting and complete clearance of stones by electrohydraulic lithotripsy. Aliment Pharmacol Ther 2003; 17: 289-96.

13. Horiuchi A, Nakayama Y, Kajiyama M, et al. Biliary stenting in the management of large or multiple common bile duct stones. Gastrointest Endosc 2010; 71: 1200-3 e2.

14. Hong WD, Zhu QH, Huang QK. Endoscopic sphincterotomy plus endo prostheses in the treatment of large or multiple common bile duct stones. Dig Endosc 2011; 23: 240-3.

15. Jain SK, Stein R, Bhuva M, Goldberg MJ. Pigtail stents: an alternative in the treatment of difficult bile duct stones. Gastrointest Endosc 2000; 52: 490-3.

16. Katsinelos P, Paroutoglou G, Kountouras J, et al. Efficacy and safety of therapeutic ERCP in patients 90 years of age and older. Gastrointest Endosc 2006; 63: 417-23.

17. Srinivasan I, Kahaleh M. Biliary stents in the millennium. Adv Ther 2011; 28: 960-72.

18. Neuhaus H, Hagenmuller F, Classen M. Self-expanding biliary stents: preliminary clinical experience. Endoscopy 1989; 21 225-8.

19. Pfau PR, Pleskow DK, Banerjee $S$, et al. Pancreatic and biliary stents. Gastrointest Endosc 2013; 77: 319-27.

20. Bergman JJ, Rauws EA, Tijssen JG, et al. Biliary endoprostheses in elderly patients with endoscopically irretrievable common bile duct stones: report on 117 patients. Gastrointest Endosc 1995; 42: 195-201.

21. Tringali A, Barbaro F, Pizzicannella M, et al. Endoscopic management with multiple plastic stents of anastomotic biliary stricture following liver transplantation: long-term results. Endoscopy 2016; 48: 546-51.

22. Katsinelos P, Galanis I, Pilpilidis I, et al. The effect of indwelling endoprosthesis on stone size or fragmentation after long-term treatment with biliary stenting for large stones. Surg Endosc 2003; 17: 1552-5.

23. Catalano MF, Linder JD, George S, et al. Treatment of symptomatic distal common bile duct stenosis secondary to chronic pancreatitis: comparison of single vs. multiple simultaneous stents. Gastrointest Endosc 2004; 60: 945-52.

24. Tsujino T, Sugita R, Yoshida H, et al. Risk factors for acute suppurative cholangitis caused by bile duct stones. Eur I Gastroenterol Hepatol 2007; 19: 585-8.

25. Barkun AN. A prospective randomised multicentre trial comparing 10F Teflon Tannenbaum stents with 10F polyethylene Cotton-Leungstents in patients with malignant common duct strictures. Gastrointest Endosc 2001; 53: 399-401.

26. Kadakia SC, Starnes E. Comparison of 10 French gauge stent with 11.5 French gauge stent in patients with biliary tract diseases. Gastrointest Endosc 1992; 38: 454-9.

27. Nuzzo G, Giuliante F, Giovannini I, et al. Advantages of multi disciplinary management of bile duct injuries occurring during cholecystectomy. Am J Surg 2008; 195: 763-9.

28. Mahajan A, Ho H, Sauer B, et al. Temporary placement of fully covered self-expandable metal stents in benign biliary strictures: mid term evaluation (with video). Gastrointest Endosc 2009; 70: 303-9.

29. Tarantino I, Traina M, Mocciaro F, et al. Fully covered metallic stents in biliary stenosis after orthotopic liver transplantation. Endoscopy 2012; 44: 246-50.

30. Banerjee N, Hilden K, Baron TH, Adler DG. Endoscopic biliary sphincterotomy is not required for transpapillary SEMS placement for biliary obstruction. Dig Dis Sci 2011; 56: 591-5.

31. Dumonceau JM, Tringali A, Blero D, et al. Biliary stenting: indications, choice of stents and results: European Society of Gastrointestinal Endoscopy (ESGE) clinical guideline. Endoscopy 2012; 44: 277-98.

Received: 18.02.2017, accepted: 27.06.2017. 